\title{
Desain Database Aplikasi Monitoring Peralatan dan Bahan Praktikum pada Lab Patologi Klinik FK UPNVJ
}

\author{
Kraugusteeliana ${ }^{1}$, \\ Sistem Informasi /Fakultas Ilmu Komputer \\ Universitas Pembangunan Nasional Veteran Jakarta \\ gusteeliana@gmail.com, kraugusteeliana@upnvj.ac.id
}

\begin{abstract}
Abstrak. Laboratorium disuatu perguruan tinggi menjadi suatu tempat kegiatan ilmiah yang dilakukan oleh mahasiswa atau dosen atau pihak lain, baik berupa praktikum, observasi, penelitian, demonstrasi dan pengembangan model-model pembelajaran yang dilakukan dalam rangka kegiatan belajar-mengajar untuk menghasilkan kualitas lulusan yang berkompetensi sesuai profil lulusan pada suatu program studi. Peningkatan layanan dan monitoring laboratorium untuk proses pembelajaran akan meningkatkan mutu dan kualitas lulusan khususnya bagi calon Dokter. Keberlangsungan kegiatan monitoring praktikum sangat diperlukan agar dapat dipastikan semua persiapan terencana dengan baik dan agar proses pembelajaran praktikum di fakultas kedokteran dapat berjalan baik dan sesuai rencana perkuliahan. Untuk itu perlu pembuatan aplikasi desain database dan monitoring data peralatan serta bahan praktikum di laboratorium dengan penelitian dilakukan dengan metode DBLC (Database Life Cycle) meliputi tahap desain model basisdata hingga tahapan user interface pengembangan aplikasi monitoring peralatan dan bahan praktikum. Aplikasi inibertujuan untuk Memudahkan kepala laboratorium dalam melakukan pendataan secara sistematis membantu kepala laboratorium dalam memonitoring dan pelaporan terkait kondisi alat laboratorium serta memonitoring ketersedian bahan praktikum untuk kegiatan belajar mengajar oleh petugas laboratorium.
\end{abstract}

Kata Kunci: DBLC, Monitoring Laboratorium, Patologi, UPNVJ

\section{Pendahuluan}

Dalam dunia pendidikan disadari adanya hubungan antara teori yang diajarkan dengan berbagai pembuktian dengan percobaan praktek. Hubungan antara teori dan praktek seyoginya bersifat berlapis-lapis yang integratif, di mana teori dan praktek secara bergantian dan bertahap saling isi mengisi, saling mencari dasar, dan saling mengkaji. Sehubungan kaitan antara teori dan praktek inilah laboratorium dan fasilitas lain dalam proses belajarmengajar patut mendapat perhatian pada saat kegiatan kerja laboratorium / laboratory work .[1]

Untuk meningkatkan efisiensi dan efektifitas pelaksanaan kegiatan praktikum dan dalam rangka meningkatkan digitalisasi pada perkantoran dalam mendukung program pemerintah Go Green / paperless maka kegiatan monitoring konvensional dapat dialihkan secara digital. Laboratorium merupakan tempat untuk melatih mahasiswa dalam hal keterampilan melakukan praktek, demonstrasi, percobaan, penelitian, dan pengembangan ilmu pengetahuan. Laboratorium dikenal juga sebagai Laboratorium Work. Laboratorium di suatu perguruan tinggi menjadi suatu tempat kegiatan ilmiah yang dilakukan oleh mahasiswa atau dosen atau pihak lain, baik berupa praktikum, observasi, penelitian, demonstrasi dan pengembangan model-model pembelajaran yang dilakukan dalam rangka kegiatan belajar-mengajar untuk menghasilkan kualitas lulusan yang berkompetensi sesuai profile lulusan pada suatu program studi.[2]

Saat ini pelaksanaan monitoring sudah baik dengan mengunakan cara manual namun perlu waktu untuk melakukan pengecekan pendataan kondisi peralatan dan pemakaian bahan praktikum. Untuk memastikan kegiatan praktikum berjalan sesuai rencana perkuliahan maka dibutuhkan pemantauan atau monitoring terhadap pengelolaan peralatan dan bahan praktikum di laboratorium. Untuk itu perlu adanya suatu mekanisme dalam pengelolaannya meliputi merencanakan, mengorganisasikan melaksanakan serta melakukan evaluasi peralatan pratikum dan bahan agar memastikan praktikum dapat terlaksana dengan baik mengunakan layanan sistem informasi. Peningkatan layanan pada era perkembangan teknologi informasi saat ini, kecepatan dan ketepatan informasi merupakan aspek penting dalam suatu organisasi agar mampu menyediakan pelayanan optimal bagi para pihak yang berhubungan [3]. Dalam upaya mendukung ketepatan dan kecepatan informasi maka dapat mengunakan Framework Laveral model Model-View-Controller (MVC) yang merupakan alternatif media manajemen informasi yang paling memungkinkan. Model MVC merupakan suatu model yang mampu 
mengembangkan website secara efektif dan efisien dilihat dari sudut pandang pengembangan, pembagian tugas, dokumentasi, pengujian dan pemeliharaan. Dengan menggunakan model MVC memungkinkan pengembangan aplikasi dibagi menjadi kasus-kasus yang lebih kecil, sehingga sistematika proses pengembangan terstruktur dengan baik [4]

Peningkatan layanan dan monitoring laboritorium untuk mempersiapan pembelajaran mengunakan sistem informasi akan sejalan dengan meningkatkan mutu dan kualitas lulusan khususnya bagi calon Dokter. Keberlangsungan kegiatan monitoring praktikum sangat diperlukan agar dapat dipastikan semua persiapan terencana dengan baik agar proses pembelajaran praktikum di fakultas kedokteran dapat berjalan baik dan sesuai rencana perkuliahan. Dengan kata lain diperlukan suatu sistem informasi manajemen monitoring di laboratorium patalogi klinik fakultas kedokteran secara berkala dan terus menerus.

Manajemen Laboratorium sebagai prosedur sistematik untuk mengumpulkan, menyimpan, mempertahankan, mengolah, mengambil dan memvalidasi data yang dibutuhkan oleh laboratorium tentang kegiatan pelayanannya untuk pengambilan keputusan manajemen [5] sehingga dengan dilakukannya manajemen laboratorium ini dapat peningkatan Mutu praktikum dan manajemen laboratorium untuk para mahasiswa. Untuk itu perlu pembuatan aplikasi desain database dan monitoring data peralatan serta bahan baku praktikum di laboratorium dengan tujuan untuk Memudahkan kepala laboratorium dalam melakukan pendataan secara sistematis membantu kepala laboratorium dalam memonitoring dan pelaporan terkait kondisi alat laboratorium serta memonitoring ketersedian bahan praktikum untuk kegiatan belajar megajar oleh petugas laboratorium.

\section{Metodologi Penelitian}

Untuk mendapatkan hasil yang baik dilakukan review penelitian terdahulu yang telah dilakukan oleh mengambil kasus pada laboratorium Biomedik Fakultas Kedokteran Universitas Brawijaya [6] terkait monitoring peralatan praktikum biomedik dengan pendekatan aplikasi berbasis Web juga penelitian mengenai Sistem Informasi Manajemen Laboratorium Patologi Anatomi Menggunakan Model MVC Berbasis Laravel Framework.[4] juga penelitian Sistem Informasi Monitoring Peminjamaan Alat Laboratorium Untuk Mahasiswa Bebasis Web Stikes Dharma Husada Bandung yan gmembahas Sistem ini dapat mengontrol keluar masuknya alat alat laboratorium yang dipinjam sehingga dapat mengurangi terjadinya kesalahan data pada proses pelaporannya. [7]

Perencanakan aktifitas kegiatan penelitiannya mengarah kepada pengembangan sistem informasi dalam meningkatkan kinerja dengan pendekatan go green atau Paperless mengedepankan pada penerapan Teknologi Informasi melalui Digitalisasi proses Bisnis Laboratorium yang dituangkan kedalam tahapan penelitian sebagai berikut:

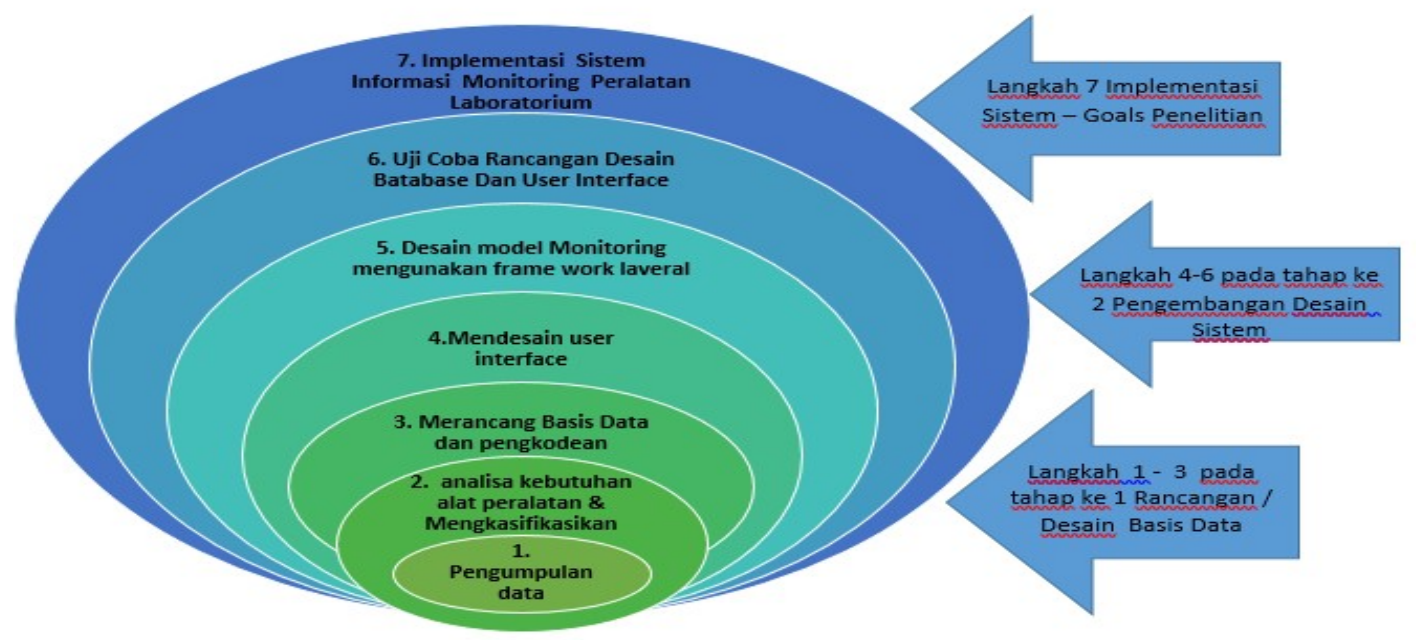

Gambar 1. Bagan tahapan Alir Penelitian

Metodelogi yang digunakan dalam aplikasi monitoring mengunakan metode Database development life cycle (DBLC) dengan tahapan pengerjaan penelitian dibagi menjadi dua tahap yaitu: 
a. tahap ke 1 design model basis Data meliputi Pengumpulan data awal, kegiatan yang dilakukan untuk mendapatkan data tentang Peralatan dan bahan praktikum yang dipergunakan; Melakukan kajian analisis terhadap kebutuhan monitoring Peralatan dan jadwal matakuliah praktikum; Melakukan kajian analisis terhadap kebutuhan monitoring bahan praktikum dan jadwal matakuliah praktikum dan pembuatan rancangan basis data dan pengkodean

b. tahapan ke 2 pengembangan aplikasi meliputi desain model monitoring dan user interface; pembuatan use case, activity proses; uji coba sistem desain database; uji coba rancangan design database dan user interface sistem informasi monitoring praktikum dan uji user interface sistem informasi monitoring praktikum.

\section{Hasil dan Pembahasan}

Dalam melakukan pratikum, pihak laboran menyiapkan peralatan dan bahan praktikum serta melakukan pendataan peralatan sesuai dengan persiapan pembelajaran praktikum permodul yang ada pada laboratorium pantologi klinik. Beberapa peralatan yang dimiliki harus disusun secara teratur pada tempat tertentu, berupa rak atau meja yang disediakan. Peralatan digunakan untuk melakukan suatu kegiatan pendidikan, penelitian dan pelayanan masyarakat atau studi tertentu. Alat-alat ini harus selalu siap pakai, agar sewaktu-waktu dapat digunakan [5]. Adapun tahapan dalam Manajemen laboratorium dimulai dari pengadaan, mengatasi permasalahan kerusakan barang pada Lab Patologi klinik UPNVJ maka ditentukanlah pengendalian proses monitoring dengan membuat mekanisme monitoring seperti terlihat pada flowchart dibawah ini:

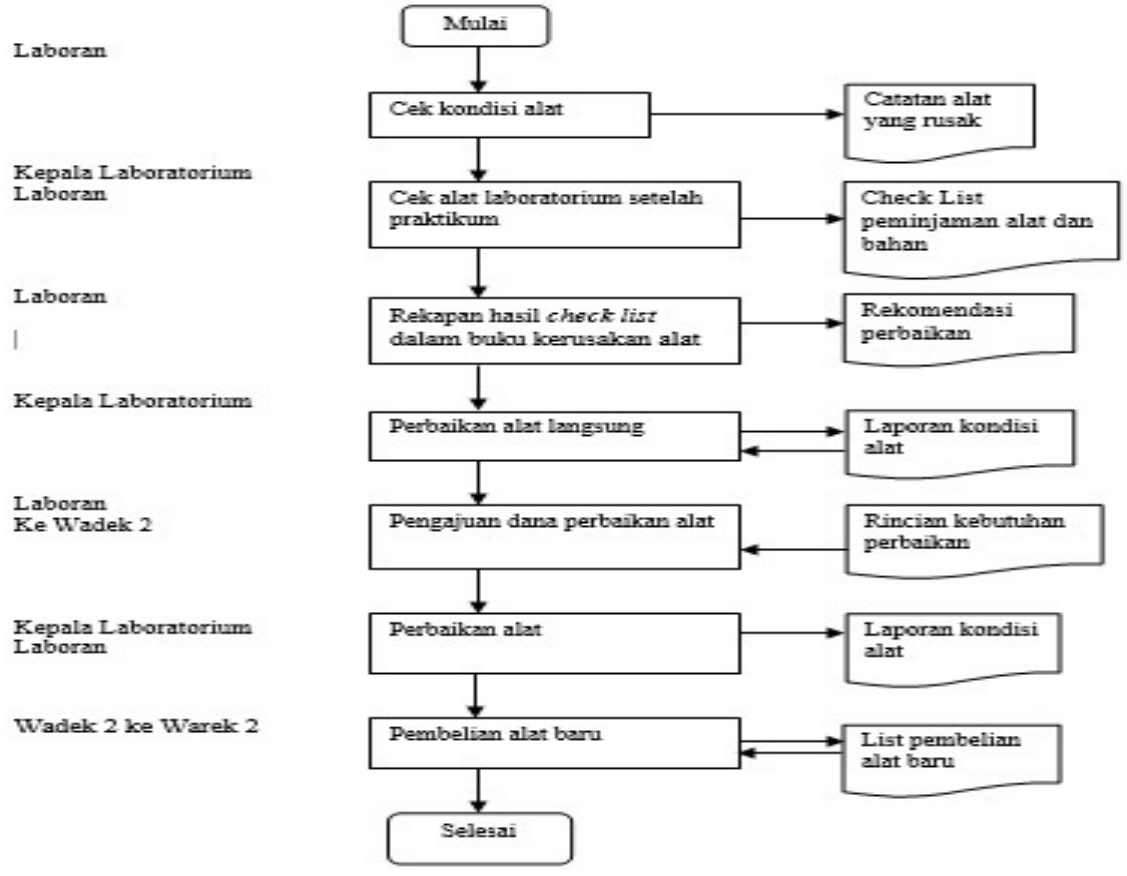

Gambar 2. Mekanisme Monitoring peralatan di Lab [1]

Pemodelan proses desain monitoring peralatan dan bahan praktikum lab patologi ini terdiri dari Use-Case Diagram, Activity Diagram, Class Diagram dan Sequence Diagram dari Unified Modeling Language (UML).

\subsection{Desain UML meliputi Diagram Use Case, Activity dan Sequence}

Use Case sebagai tahapan untuk pengembangan sebuah software atau sistem informasi untuk menangkap kebutuhan fungsional dari sistem yang akan dibangun atau dirancang untuk mengambarkan sistem , lingkungan didalam maupun luar sistem serta hubungan yang terjadi didalam sistem. Berikut ini gambaran dari desain UML pada desain aplikasi monitoring laboratorium, seperti dibawah ini: 


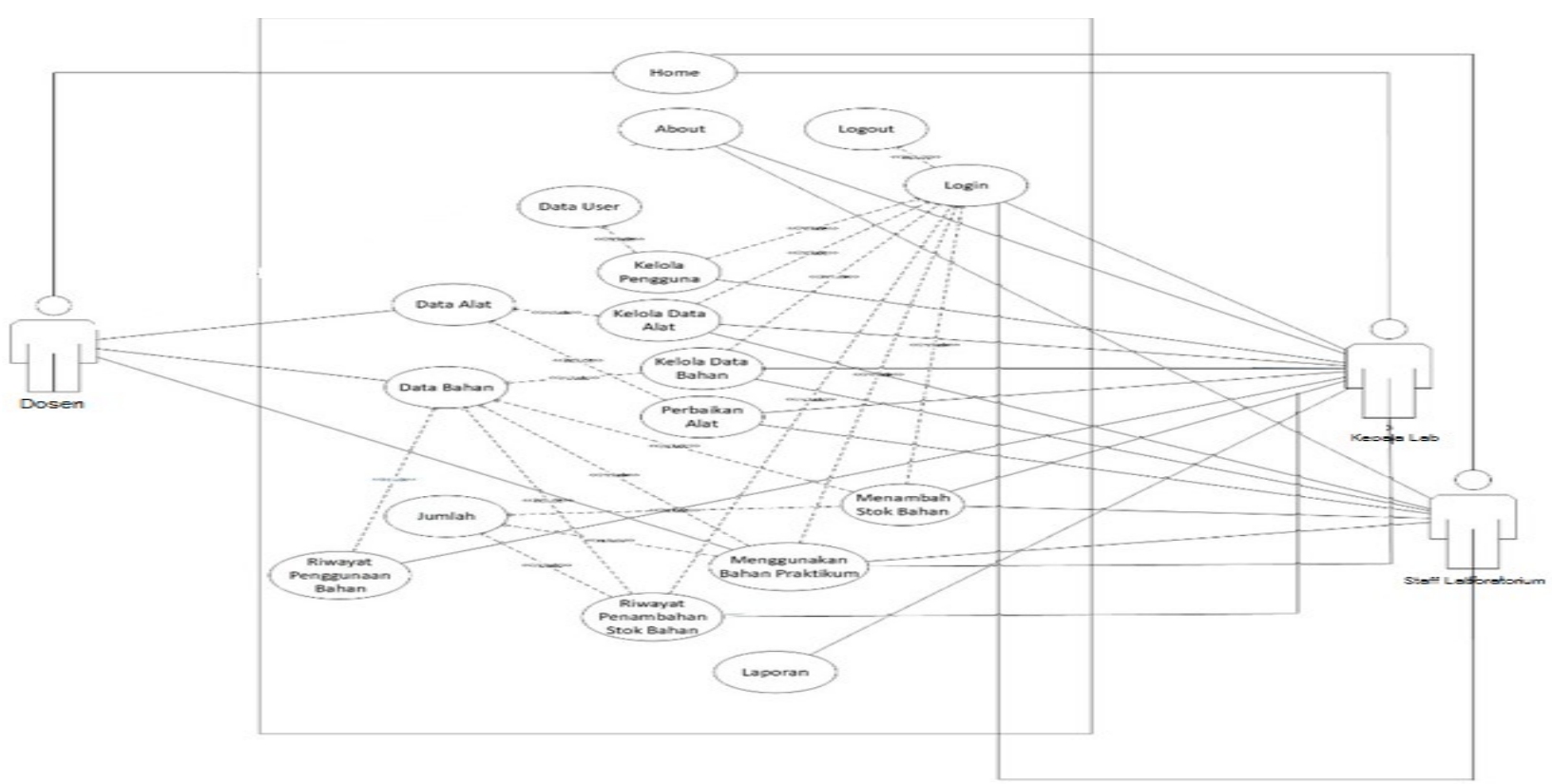

Gambar 3. Use Case Diagram keseluruhan Monitoring peralatan di Lab

Tabel 1. Use CaseActor dalam Sistem Aplikasi Monitoring alat dan bahan praktikum

\begin{tabular}{|lll|}
\hline $\mathbf{1}$ & Actor & \multicolumn{1}{c|}{ Deskripsi Peranaan dalam system } \\
& & a. Mengelola proses kelola pengguna \\
& & b. Mengolah data alat dan bahan praktikum, \\
& & c. Melihat penggunaan bahan \\
& d. Melihat riwayat penggunaan alat \\
& & e. Mencetak laporan \\
\hline $\mathbf{2}$ & Dosen & a. Mengeceak bahan untuk praktukum sesuai modul pembelajaran \\
& & b. Mengunakan bahan dan peralatan praktikum \\
\hline 3 & Staff Laboratorium & a. Mengelola data alat mulai dari menambah alat baru, jumlah, informasi dan \\
& & gambar peralatan \\
& & b. Menambahkan bahan praktikum \\
& & c. Mengkontrol pengunaan bahan dan peralatan praktikum \\
& d. Mengecek status peralatan dan Melaporkan Kerusakan \\
& e. Mendata penggunaan alat \\
& f. Menambah informasi peralatan baru dalam bentuk gambar dan informasi \\
\end{tabular}


Aktivitas kegiatan monitoring antara lain kelola peralatan, bahan praktikum, pengecakan stock bahan praktikum serta pelaporan dilakukan untuk memonitoring pelaksanaan praktikum berjalan baik seperti terlihat pada gambar 2- aktivitas monitoring peralatan, gambar 3- aktivitas monitoring bahan praktikum dan sequence dari rancangan aplikasi bagi kepala laboratorium atau kepala Lab pada gambar-4.

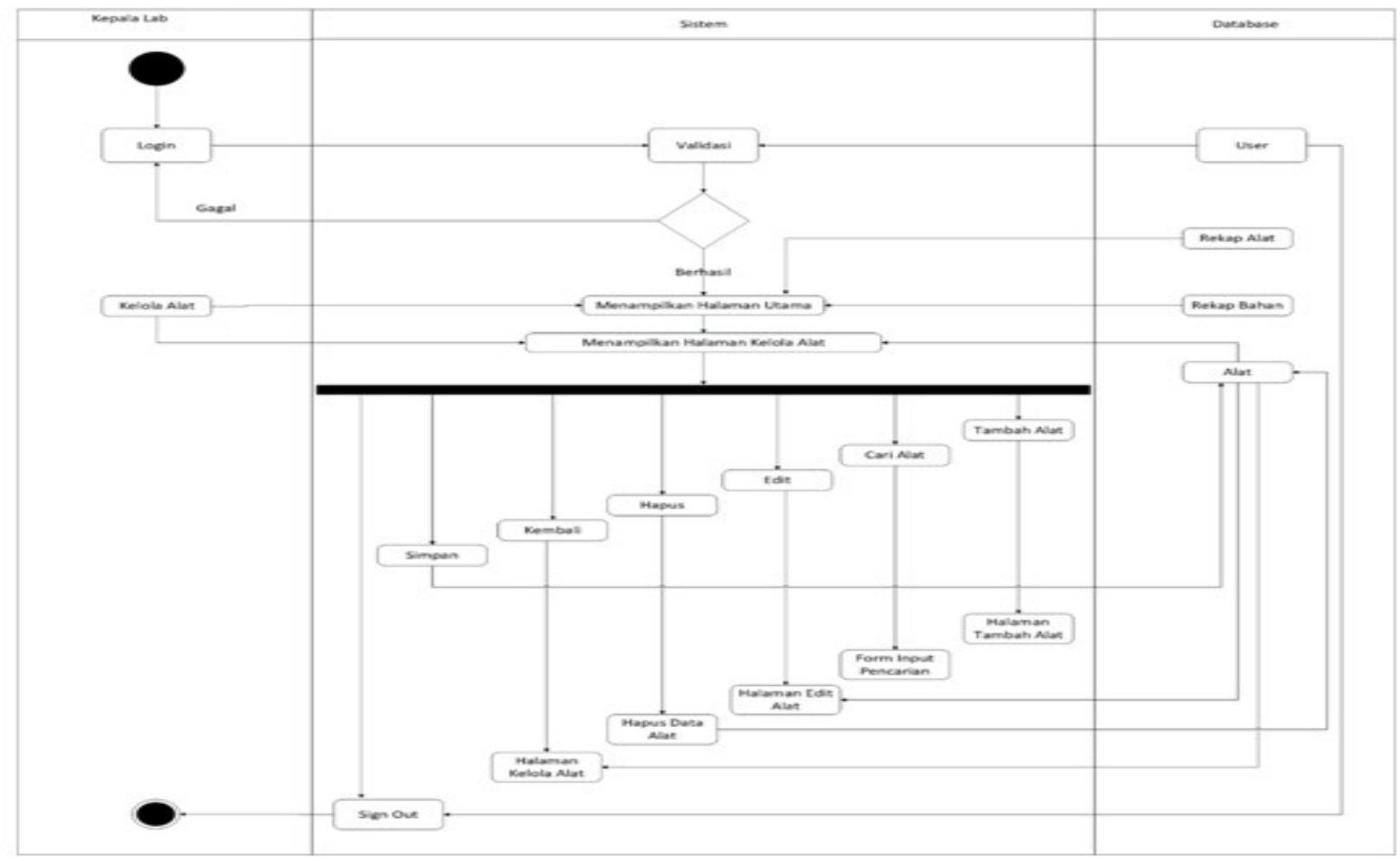

Gambar 4 Activity Diagram monitoring peralatan

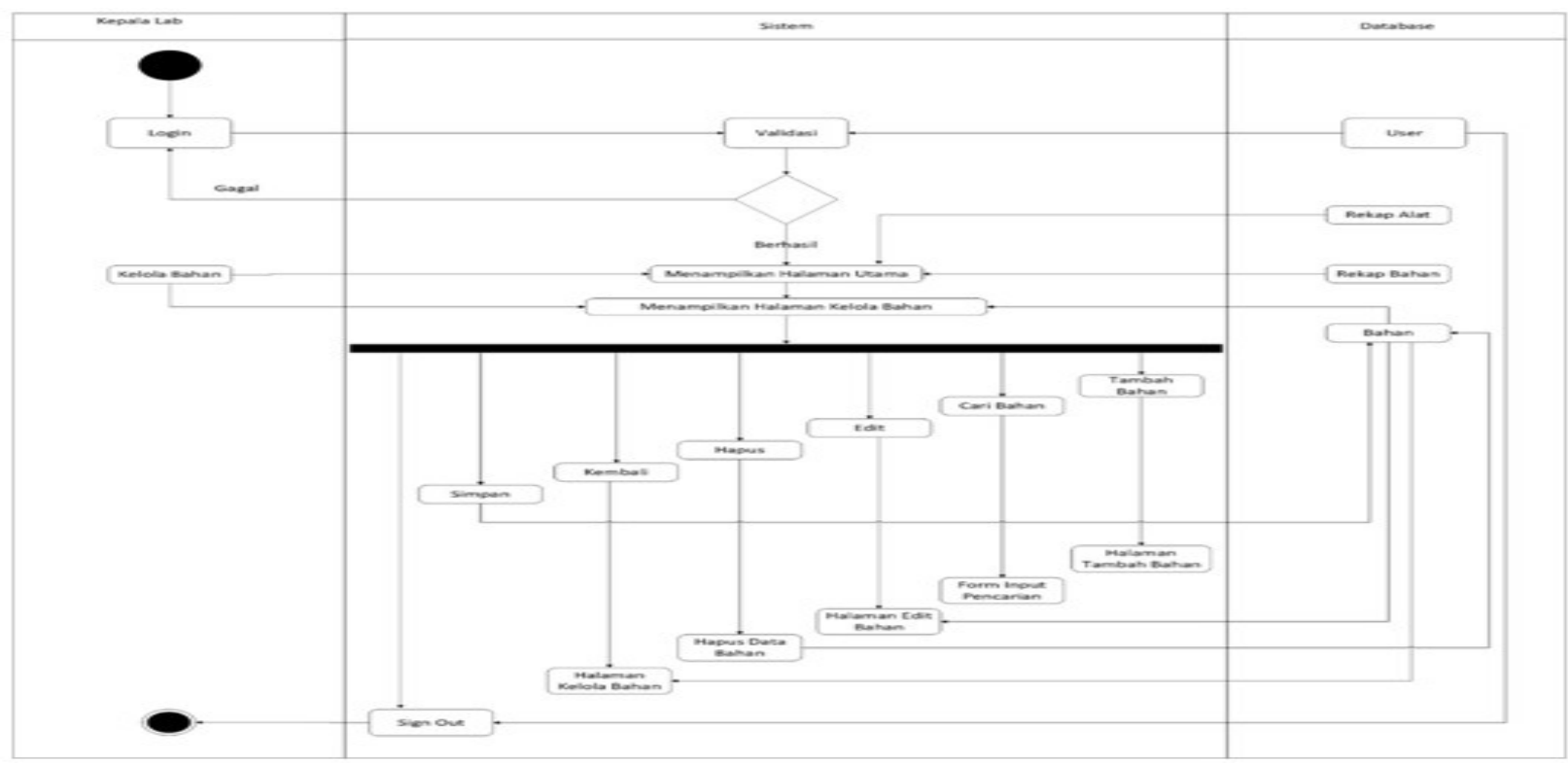

Gambar 5 Activity Diagram monitoring bahan praktikum 


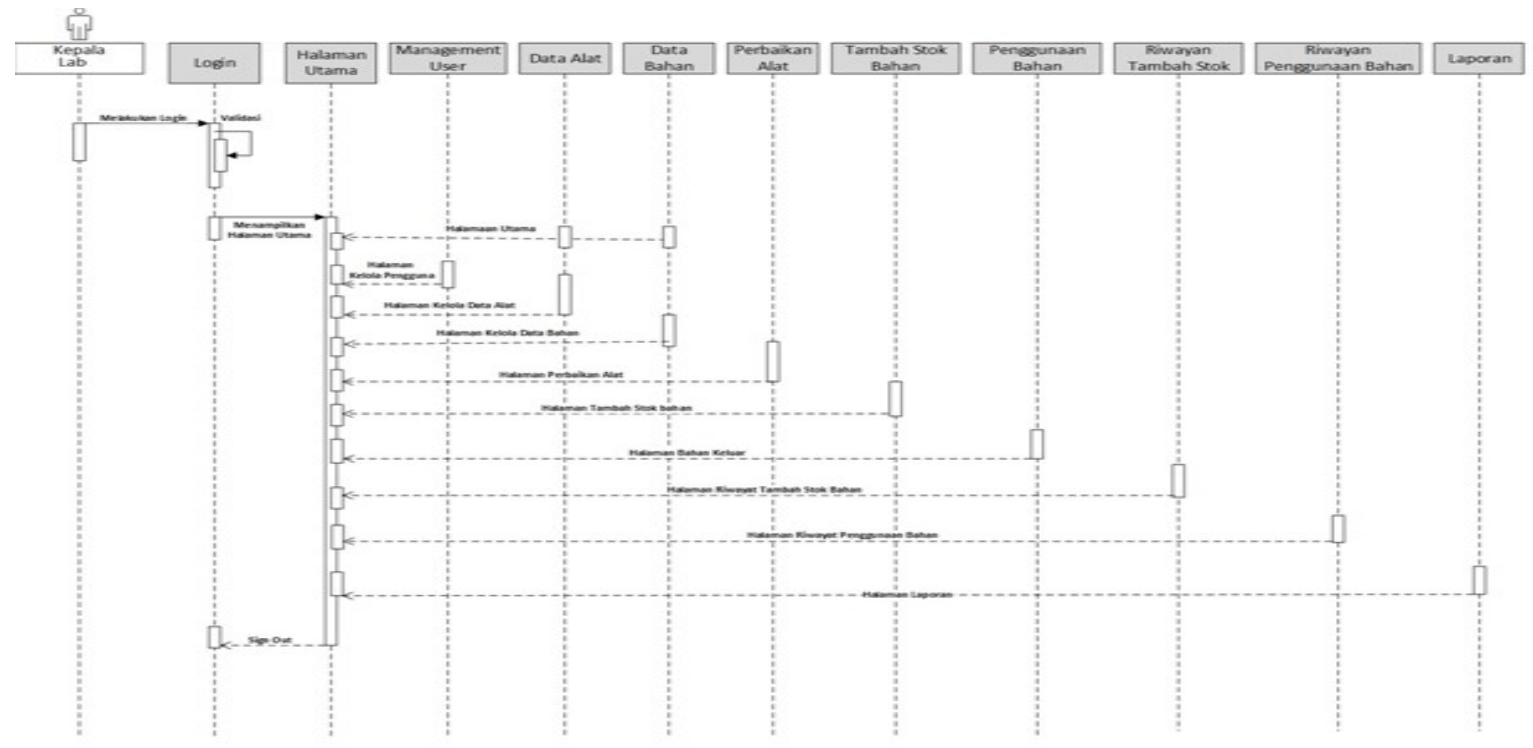

Gambar 6 Sequense Diagram monitoring oleh kepala Lab untuk memonitor peralatan dan bahan praktikum

\subsection{Desain Database Logik}

Pada tahap ini telah dilakukan analisis kebutuhan data berdasarkan observasi langsung dan wawancara kepada pihak pengelola laboratorium patologi sehingga didapat kebutuhan data fisik dengan menghasilkan 7 buah tabel / file data yang akan dipergunakan dalam aplikasi monitoring ini terdiri dari tabel user, tabel alat, tabel bahan , tabel perbaikan alat, tabel inventaris BMN, tabel pemasukan alat dan bahan dan tabel pengeluaran alat dan bahan, sepeti terlihat pada relasi gambar 6 .

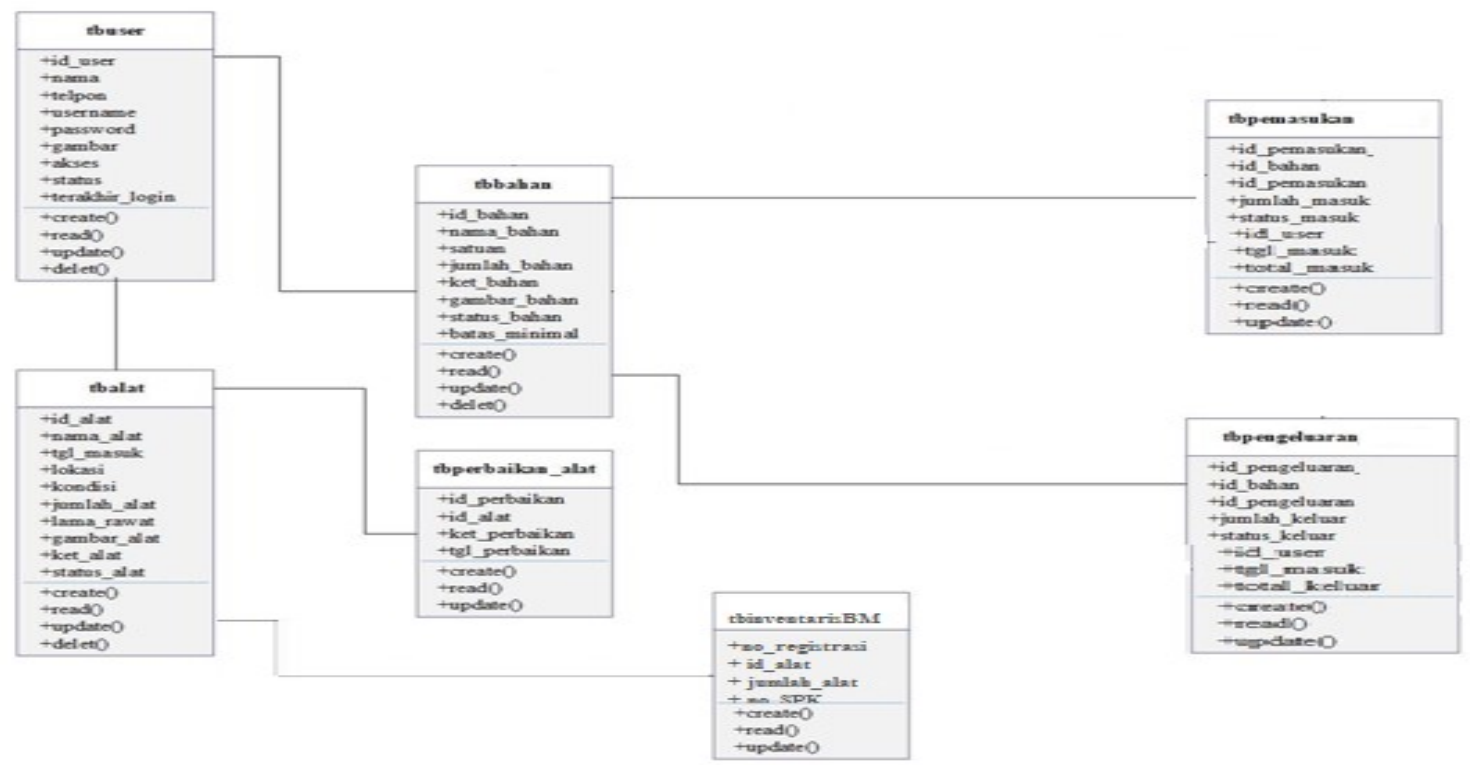

Gambar 7. Desain Logic Database aplikasi monitoring peralatan dan bahan praktikum Lab

Setelah dilakukan perancangan logic, tahapan selanjutnya merancang kebutuhan database fisik yang menunjukan struktur dari elemen-elemen data menyatakan panjang elemen data dan jenis-jenis datanya yang dipergunakan dalam aplikasi. Tahapan perancangan fisik basisdata sebagai berikut 
1) Struktur tabel_inventaris BMN

Tabel 2. Inventaris BMN

\begin{tabular}{|r|l|c|c|c|}
\hline \multicolumn{1}{|c|}{ No } & Nama & Tipe Data & Size & Ket \\
\hline $\mathbf{1}$ & No_registrasi & varchar & 11 & PK \\
\hline $\mathbf{2}$ & Id_Alat & varchar & 30 & \\
\hline $\mathbf{3}$ & Jml_alat & int & 3 & \\
\hline $\mathbf{4}$ & No_SPK & varchar & 26 & \\
\hline
\end{tabular}

2) Struktur tabel user

\begin{tabular}{|r|c|c|c|c|}
\hline \multicolumn{1}{|c|}{ No } & Nama & Tipe Data & Size & Ket \\
\hline $\mathbf{1}$ & id_user & varchar & 8 & PK \\
\hline $\mathbf{2}$ & nama & varchar & 30 & \\
\hline $\mathbf{3}$ & telpon & int & 12 & \\
\hline $\mathbf{4}$ & username & varchar & 30 & \\
\hline $\mathbf{5}$ & password & varchar & 8 & \\
\hline $\mathbf{6}$ & gambar & blob & & \\
\hline $\mathbf{7}$ & akses & varchar & 30 & \\
\hline $\mathbf{8}$ & status & char & 10 & \\
\hline
\end{tabular}

3) Struktur tabel alat

Tabel 4. Alat
\begin{tabular}{|c|l|c|c|c|}
\hline No & Nama & Tipe Data & Size & Ket \\
\hline $\mathbf{1}$ & id_alat & varchar & 8 & PK \\
\hline $\mathbf{2}$ & tgl_masuk & date & & \\
\hline $\mathbf{3}$ & nama_alat & varchar & 30 & \\
\hline $\mathbf{4}$ & Lokasi & varchar & 30 & \\
\hline $\mathbf{5}$ & Kondisi & int & 3 & \\
\hline $\mathbf{6}$ & Jumlah & int & 3 & \\
\hline $\mathbf{7}$ & lama_rawat & int & 3 & \\
\hline $\mathbf{8}$ & ket_alat & text & & \\
\hline $\mathbf{9}$ & gambar_alat & blob & & \\
\hline $\mathbf{1 0}$ & status_alat & char & 10 & \\
\hline $\mathbf{1 1}$ & No_Rak_Alat & Char & 8 & \\
\hline $\mathbf{1 2}$ & Lokasi & Char & 20 & \\
\hline
\end{tabular}

4) Struktur tabel bahan

Tabel 5. Bahan

\begin{tabular}{|r|l|c|c|c|}
\hline \multicolumn{1}{|c|}{ No } & Nama & Tipe Data & Size & Ket \\
\hline $\mathbf{1}$ & id_bahan & varchar & 8 & PK \\
\hline $\mathbf{2}$ & nama_bahan & varchar & 30 & \\
\hline $\mathbf{3}$ & Satuan & char & 5 & \\
\hline $\mathbf{4}$ & jumlah_bahan & double & & \\
\hline $\mathbf{5}$ & ket_bahan & text & & \\
\hline $\mathbf{6}$ & gambar_bahan & blob & & \\
\hline $\mathbf{7}$ & status_bahan & varchar & 10 & \\
\hline $\mathbf{8}$ & batas_minimal & int & 3 & \\
\hline $\mathbf{9}$ & No_Rak_Alat & Char & 8 & \\
\hline $\mathbf{1 0}$ & Lokasi & Char & 20 & \\
\hline
\end{tabular}

5) Struktur tabel perbaikan alat

Tabel 6. Perbaikan Alat

\begin{tabular}{|r|l|c|c|c|}
\hline No & Nama & Tipe Data & Size & Ket \\
\hline $\mathbf{1}$ & id_perbaikan & varchar & 8 & PK \\
\hline $\mathbf{2}$ & id_alat & varchar & 8 & \\
\hline $\mathbf{3}$ & tgl_perbaikan & date & & \\
\hline $\mathbf{4}$ & ket_perbaikan & Text & & \\
\hline
\end{tabular}


6) Struktur tabel pemasukan alat \& bahan

Tabel 7. Pemasukan Alat dan Bahan

\begin{tabular}{|r|l|c|c|c|}
\hline \multicolumn{1}{|c|}{ No } & Nama & Tipe Data & Size & Ket \\
\hline $\mathbf{1}$ & id_pemasukan & int & 8 & PK \\
\hline $\mathbf{2}$ & id_user & varchar & 8 & \\
\hline $\mathbf{3}$ & tgl_masuk & date & & \\
\hline $\mathbf{4}$ & total_masuk & double & & \\
\hline $\mathbf{5}$ & id_bahan & varchar & 8 & \\
\hline $\mathbf{6}$ & jumlah_Masuk & double & & \\
\hline $\mathbf{7}$ & status_Masuk & char & 10 & \\
\hline
\end{tabular}

7) Struktur tabel pengeluaran alat $\&$ bahan

Tabel 8. Pengeluaran dan Bahan
\begin{tabular}{|r|l|c|c|c|}
\hline \multicolumn{1}{|c|}{ No } & Nama & Tipe Data & Size & Ket \\
\hline $\mathbf{1}$ & id_pengeluaran & int & 8 & PK \\
\hline $\mathbf{2}$ & id_user & varchar & 8 & \\
\hline $\mathbf{3}$ & tgl_keluar & date & & \\
\hline $\mathbf{4}$ & total_keluar & double & & \\
\hline $\mathbf{5}$ & id_bahan & varchar & 8 & \\
\hline $\mathbf{6}$ & jumlah_keluar & double & & \\
\hline $\mathbf{7}$ & status_keluar & char & 10 & \\
\hline
\end{tabular}

\subsection{Desain Aplikasi User Interface}

Desain user interface sangat dirancang untuk memudahkan pengguna sistem monitoring ini untuk melakukan pengelolaan alat dan bahan praktikum serta mengontrol pengunaan pemakaiannyabaik peralatan masuk, keluar maupun jika terjadi kerusakan pada peralatan, seperti terlihat pada gambar desain aplikasi berikut ini:

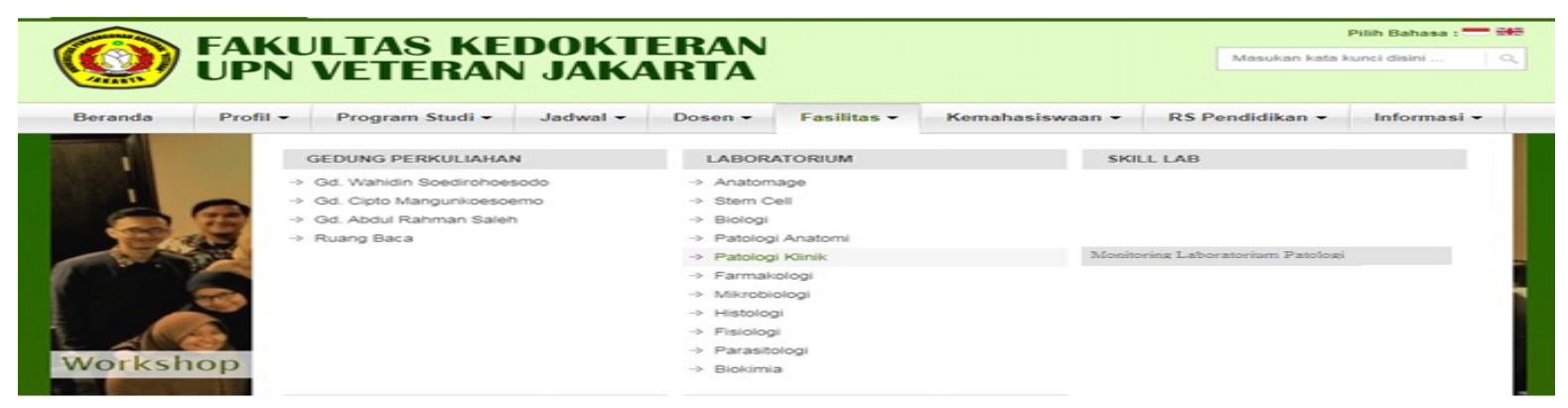

Gambar 7 Desain User Interface aplikasi monitoring

Pada gambar 7 terdapat user interface menu home web fakultas kedokteran pada menu fasillitas laboratorium patologi lalu pilih monitoring laboratorium maka akan tampil menu login untuk masuk kedalam sistem monitoringnya seperti terlihat pada gambar 8 dibawah ini:.

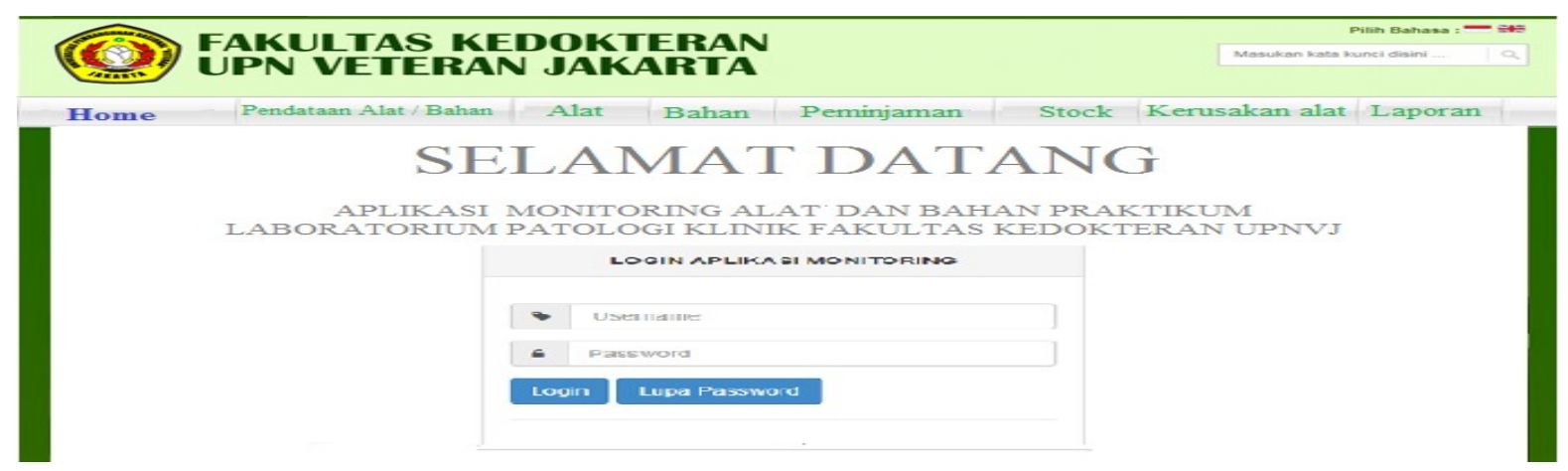

Gambar 8 Desain User interface untuk Menu Home dan Login ke aplikasi Monitoring alat dan bahan praktikum 
Home Pendataan Alat/Bahan Alat Bahan Peminjaman Stock Kerusakan alat Laporan

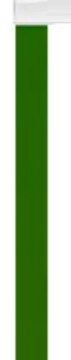
INPUT ALAT PRAKTIKUM

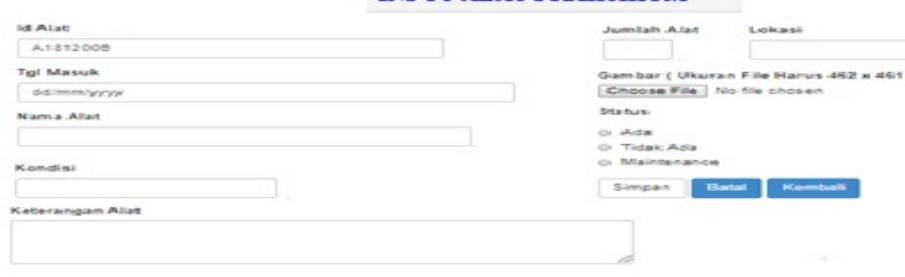

Gambar 9 Desain User interface untuk Menu Input Peralatan Praktikum

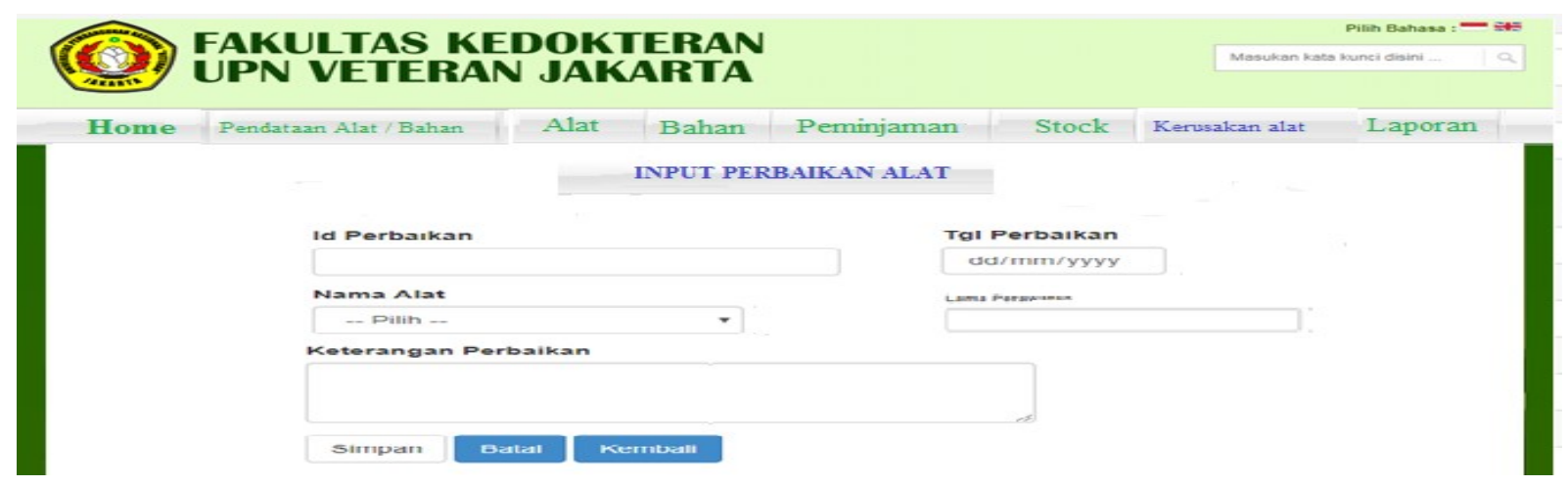

Gambar 10 Desain User interface untuk Menu Input Perbaikan Peralatan

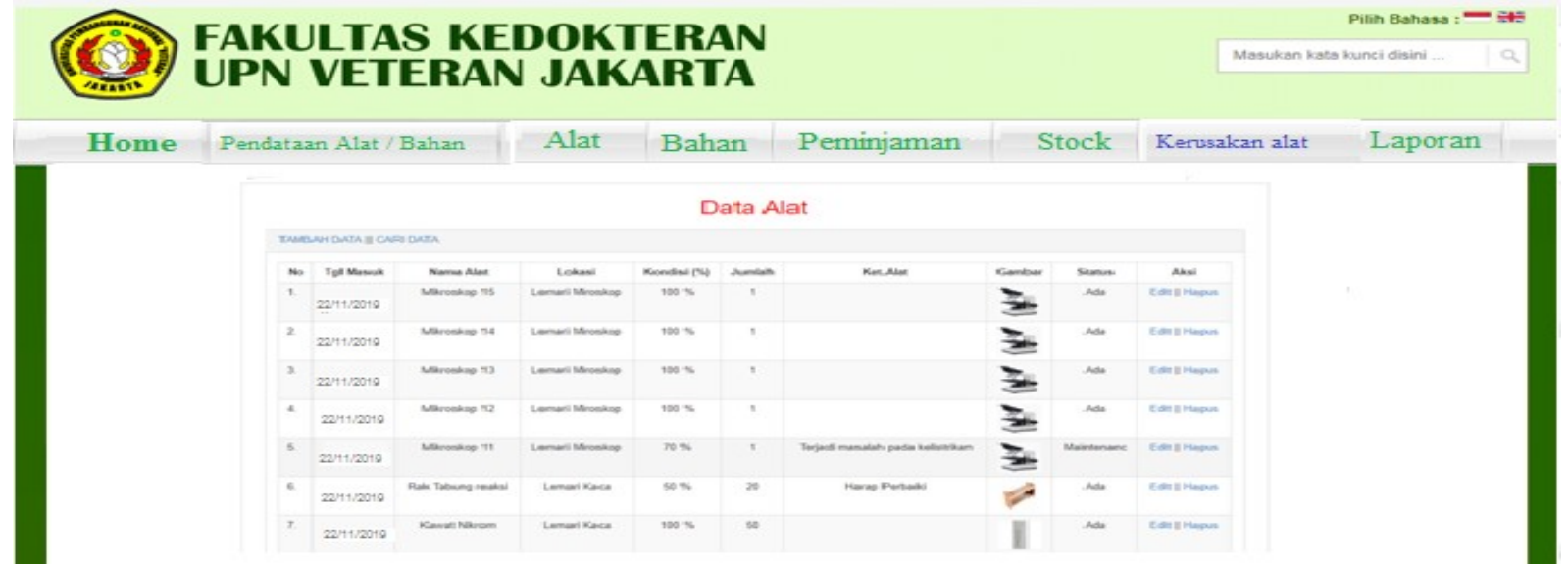

Gambar 11 Desain User interface untuk Menu Data Peralatan Praktikum

User interface pada gambar 8 untuk menginput data peralatan yang baru dibeli kemudian jika ada barang yang rusak maka dilakukan input data perbaikan yang akan mempengaruhi stock peralatan pada menu pendataan peralatan sehingga akan mempermudah staff laboratorium untuk melaporkan kepada kepala Lab dan dosen yang akan mengajar terkait persediaan alat praktikum dan bahan yang akan digunakan. Sedangkan gambar 10 menjelaskan mengenai data alat meliputi informasi stock, kondisi alat disertai gambar alat tersebut. 


\section{Kesimpulan dan Saran}

\subsection{Kesimpulan}

Melalui Desain database aplikasi monitoring peralatan dan bahan dapat lebih memudahkan kepala laboratorium dalam melakukan pendataan secara sistematis, membantu kepala laboratorium dalam memonitoring dan pelaporan terkait kondisi alat laboratorium juga bahan praktek sehingga kegiatan praktikum dalam proses belajar mengajar akan berlangsung dengan lancar tanpa kendala baik untuk peralatan maupun bahan praktikum.

\subsection{Saran}

Sistem Aplikasi monitoring akan lebih baik jika dikembangakan dengan mengacu standar internasional operasional laboratorium ISO/IEC 17025:2017 "General requirements for the competence of testing and calibration laboratories' dengan memperhatikan klausal secara keseluruhannya

\section{Referensi}

[1] Mustaji. Laboratorium: Perspektif Teknologi Pembelajaran. Dalam internet online: http://pasca.tp.ac.id/site/laboratorium-perspektif-teknologi-pembelajaran 2009.

[2] Kraugusteeliana. "Rancang bangun desain system informasi monitoring praktikum pada laboratorium patologi klinik fakultas kedokteran UPN Vetran Jakarta berbasis web mengunakan framework Laravel". Senasikesi ke 2. (2019)

[3] Widarno, "Efektivitas Perencanaan dan Pengembangan Sistem Informasi," Jurnal Akuntansi dan Sistem Teknologi Informasi, Vol.6 No.1, 2008

[4] Dwiza Riana, Rangga \& Dkk. Sistem Informasi Manajemen Laboratorium Patologi Anatomi Menggunakan Model MVC Berbasis Laravel Framework. KNSI 2018

[5] Retno sari \& Tety Resmiaty. Bahan Ajar Teknologi Laboratorium Medis Aplikasi Sistem Informasi dan Majemena Laboratorium. Kementrian Kesehatan RI. 2017

[6] Leo A. Yudanto \& dkk Rancang Bangun Aplikasi Sistem Informasi Manajemen Laboratorium Biomedik Fakultas Kedokteran Universitas Brawijaya Jurnal Pengembangan Teknologi Informasi dan Ilmu Komputer e-ISSN: 2548-964X Vol. 1, No. 8, Juni 2017, hlm. 628-63

[7] Nana Rukmana Sistem Informasi Monitoring Peminjamaan Alat Laboratorium Untuk Mahasiswa Bebasis Web Stikes Dharma Husada Bandung (2015) 